\title{
ВЛИЯНИЕ ЗАНЯТИЙ СКАНДИНАВСКОЙ ХОДЬБОЙ В ЛЕСУ НА ПСИХОЭМОЦИОНАЛЬНОЕ СОСТОЯНИЕ СТУДЕНТОВ АГМУ В ДИНАМИКЕ ОСЕНЬ-ВЕСНА
}

\author{
Бардакова А.Ю., Суркова А.Д., Лобыгина Н.М. (Алтайский государственный \\ медицинский университет, Барнаул, Россия) \\ alexandrabardakova@mail.ru,nikulina.nas@yandex.ru, lobygina@bk.ru

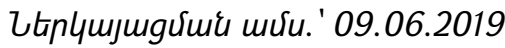

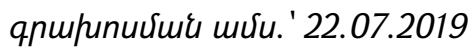

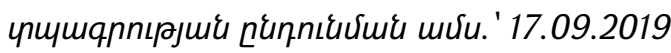

В данной статье мы проанализировали взаимосвязь между занятиями скандинавской ходьбой на "свежем воздухе» и изменением психоэмоционального фона учащихся АГМУ, а также причины, которые могли вызвать данные изменения. Предложили эффрективное практическое применение полученной информации.

Ключевые слова: Люшер, скандинавская ходьба, студенты, тест, психоэмочиональное состояние, стресс, лес.

Введение. В настоящее время эмоциональный стресс является одним из ведущих факторов, влияющих на функциональное состояние человека и способных вызывать нарушения здоровья. Данная проблема актуальна и для студентов АГМУ, особенно на начальных этапах обучения в связи с изменением динамического стереотипа и формированием новых форм обучения. Тем не менее отмечается сохранение состояния тревожности на протяжении всего периода обучения, что связано с усвоением большого объема учебного материала, приводящим к систематическим интенсивным психоэмоциональным нагрузкам. Кроме того, известно, что климатогеографический фактор имеет значительный вес в формировании адаптивно-приспособительных реакций. В XIX веке философ Кьеркегор говорил, что все психологические проблемы решаются при помощи двадцатиминутной энергичной прогулки. Целью настоящей работы является определение взаимосвязи между занятиями скандинавской ходьбой и психоэмоциональным состоянием студентов АГМУ, а также выявление сезонной динамики в период осень-весна.

Материалы и методы. Исследование проводилось в октябре 2017 года (осень) и в апреле 2018 года (весна). В эксперименте приняли участие студенты разных групп без ограничения по состоянию здоровья, общей численностью 50 человек. Для изучения эмоционального состояния испытуемых был применен Метод цветовых выборов (МЦВ) в модификации Собчик (2006) (он представляет собой адаптированный вариант цветового теста М. Люшера (1971), который был предложен студентам перед и после тридцатиминутной скандинавской ходьбы. 
Тест представляет собой набор из восьми цветовых эталонов. Испытуемому предлагается составить из разложенных перед ним цветовых карточек ряд, начиная с самого приятного цвета, сообразуясь с тем, насколько этот цвет предпочитаем в сравнении с другими при данном имеющемся выборе и в данный момент, и заканчивая самым неприятным[1]. Далее записать эту последовательность в виде цифр. Первый выбранный цвет характеризует желаемое состояние, второй действительное.

\section{Результаты исследования:}

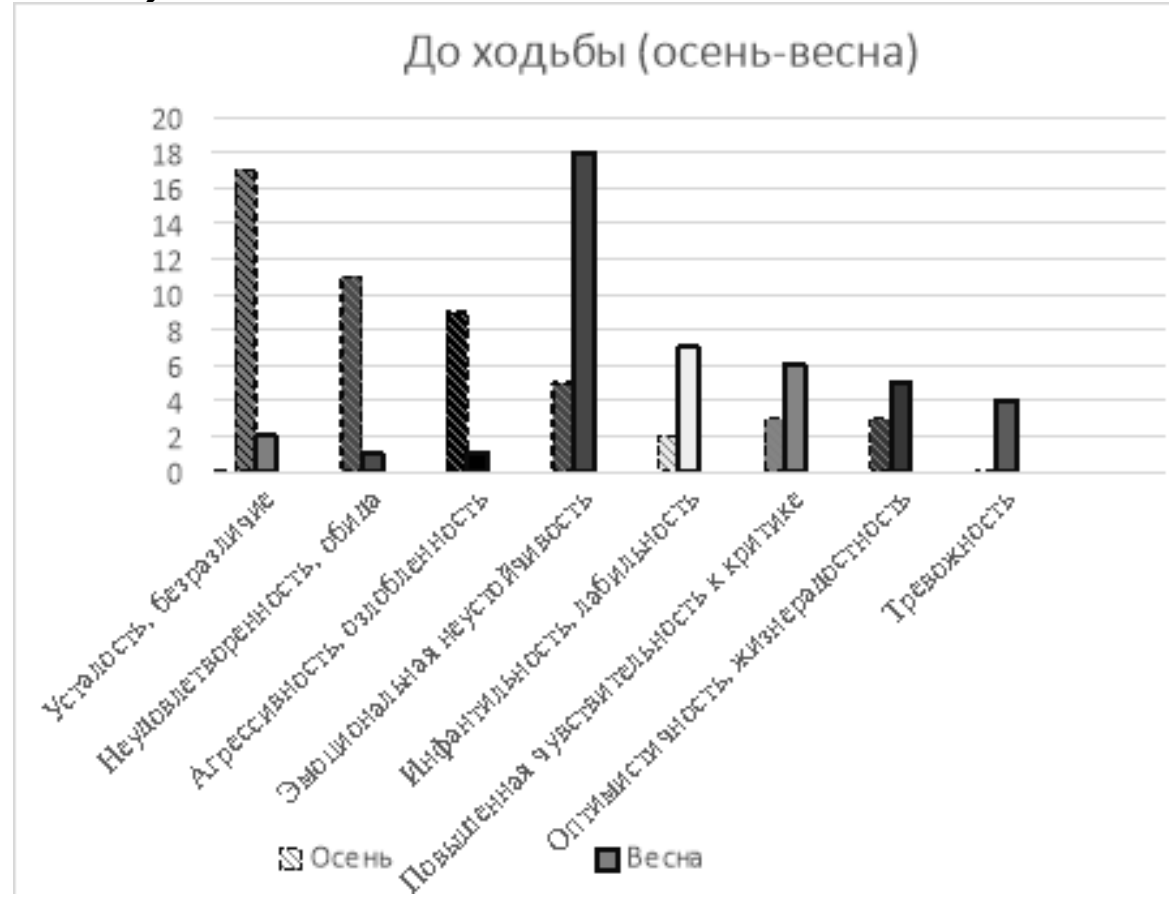

Pис.1 Результаты теста Люшера до занятия по скандинавской ходьбе.

На данной гистограмме отчетливо видно, что осенью треть опрошенных (34\%) приступило к занятию в состоянии усталости и безразличия к чему бы то ни было, немногим меньше (22\%) с чувством неудовлетворенности, обиды, $(18 \%)$ начали выполнение задания агрессивными и озлобленными. Так же у (10\%) была отмечена нетерпеливость и эмоциональная незрелость, у (4\%) повышенная чувствительность к критике, инфантильность, лабильность. И лишь у (6\%) отмечались оптимизм и жизнерадостность. Весной перед ходьбой у испытуемых на первых позициях преобладали такие цвета, как фиолетовый (36\%), что соответствует эмоциональной неустойчивости, напряженности; жёлтый (14\%), что говорит о инфантильности, лабильности; зеленый (12\%) - повышенная чувствительность к критике; красный (10\%)-оптимистичность, жизнерадостность. 


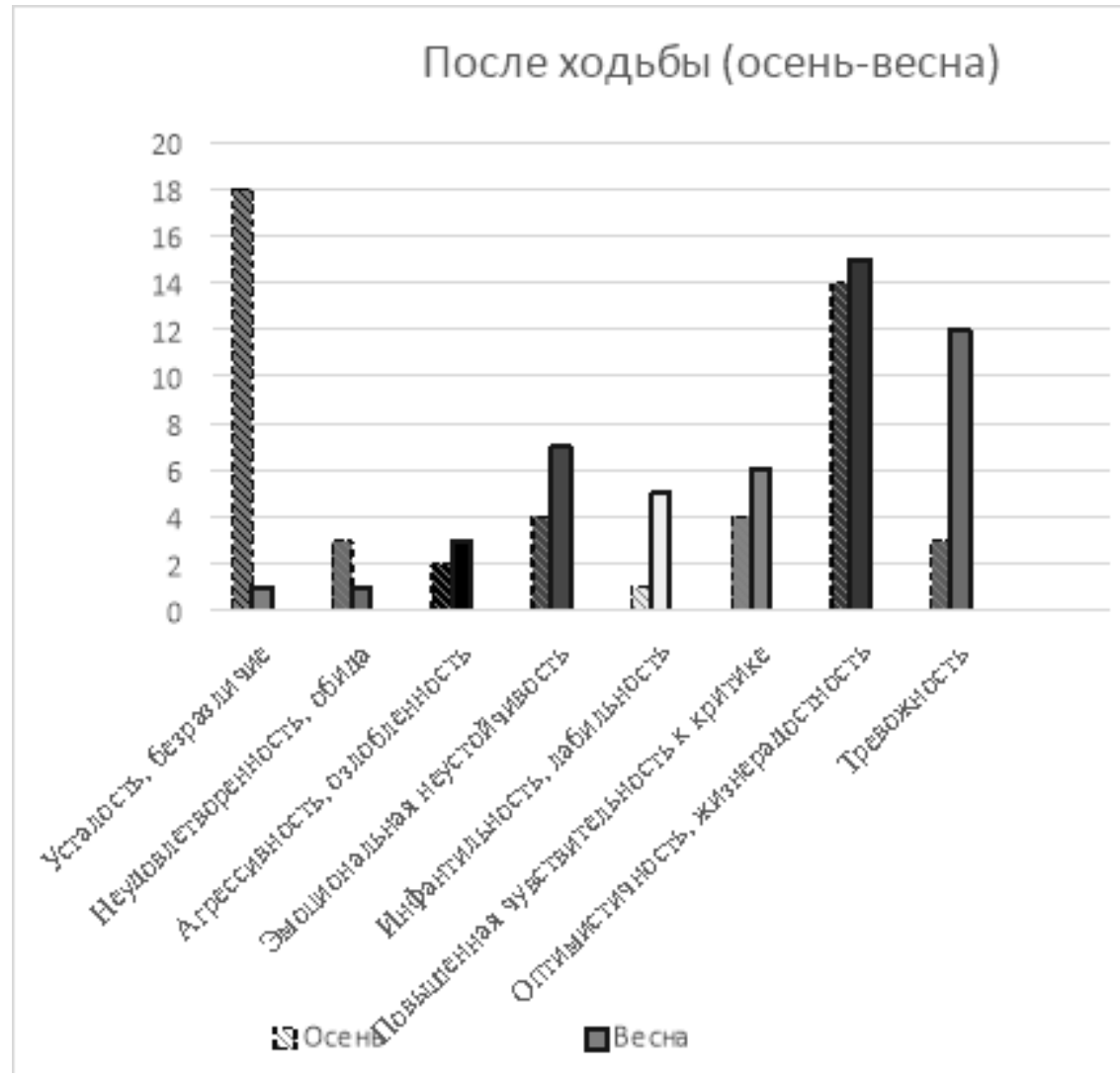

Pис.2 Результаты теста Люшера после занятия по скандинавской ходьбе.

Получив данные после завершения занятия, мы отметили серьезные изменения в соотношении психоэмоциональных статусов у студентов. Осенью С (6\%) до (34\%) выросло число с оптимистичностью и жизнерадостностью, а неудовлетворенность и агрессивность снизились до (6\%). Остальные показатели не подверглись таким большим изменениям. Усталость выросла с (34\%) до (36\%), скорее всего за счет того, что для некоторых испытуемых физические нагрузки оказались слишком большими, также появилась повышенная тревожность (6\%), которая не наблюдалась до начала эксперимента. Весной также видны значительные изменения: оптимистичность, жизнерадостность выросла с (10\%) до (30\%); снизился процент эмоциональной неустойчивости, напряженности с $(36 \%)$ до $(14 \%)$, но возрос уровень тревожности с (8\%) до (24\%).

Из полученных результатов видно, что доля испытуемых с позитивным и жизнерадостным психоэмоциональным статусом, значительно увеличилась именно за счет людей с неудовлетворенностью, обидой и агрессией. Вполне возможно, что причиной этому послужила некритическая физическая нагрузка, которая 
спровоцировала выработку эндорфинов повысивших эмоциональный фон и вызвавших «эйфорию бегуна», а также психотерапевтический эффрект леса и его атмосферы.

Выводы: нами получены данные, которые подтверждают наличие прямой взаимосвязи между занятиями скандинавской ходьбой в лесу и заметным снижением уровня агрессии и обиды среди студентов. Исходя из этого можно заключить, что данный вид физических нагрузок крайне полезен для снятия эмоционального напряжения и снижения общего уровня стресса. Это в свою очередь, в дальнейшем будет служить профилактикой различных психосоматических патологий.

\section{Литература}

1. Линдберг А. Марафон здоровья. Скандинавская ходьба и джоггинг. От первых шагов до спортивной трассы / Александр Линдберг. - М.: Вектор, 2015. - 256c.

2. Полетаева А. Лечебная фризкультура. Скандинавская ходьба. Секреты известного тренера (комплект из 2 книг) / Анастасия Полетаева, Лилия Шельмина, Николай Балашов. - М.: Питер, 2015. - 304 с.

3. Собчик Л.Н. Модификация цветового теста Люшера / Л. Н. Собчик. - М.: Питер, 2013. -123 с.

4. Эткинд А.М. Цветовой тест отношений. //Общая психодиагностика. М., 1987. 221-227 c.

5. Фрилинг Г., Ауэр К. Человек, цвет, пространство. М., 1973 - 316 с.

\section{THE INFLUENCE OF NORDIC WALKING IN THE FOREST ON THE EMOTIONAL STATE OF STUDENTS OF ALTAI STATE MEDICAL UNIVERSITY}

Bardakova A. Y. Surcova A. D., Lobygina N. M. (Altai state medical University, Barnaul, Russian Federation)

In this article, we examined the relationship between Nordic walking on "fresh air" and change the emotional background of students, as well as the causes that might trigger these changes. It was suggested that effective practical application of the information received.

Keywords: Luscher, Nordic walking, students, test, emotional state, stress, forest. 